Strahlenther Onkol 2013 · 189:618-624

DOI 10.1007/s00066-013-0397-z

Received: 31 December 2012

Accepted: 22 May 2013

Published online: 4 July 2013

(c) Springer-Verlag Berlin Heidelberg 2013
J.O. Brömme ${ }^{1} \cdot$ M. Schmücking ${ }^{1}$ A. Arnold ${ }^{2} \cdot$ R. Giger ${ }^{2} \cdot$ D. Rauch ${ }^{3} \cdot$ D. Leiser ${ }^{1}$. L. Plasswilm ${ }^{4} \cdot$ A. Geretschläger ${ }^{1} \cdot$ P. Ghadjar ${ }^{1}$ • D.M. Aebersold ${ }^{1}$

${ }^{1}$ Department of Radiation Oncology, Inselspital, Bern University Hospital and University of Bern

${ }^{2}$ Head and Neck Surgery, Inselspital, University of Bern

${ }^{3}$ Medical Oncology, Inselspital, University of Bern

${ }^{4}$ Radiation Oncology, Kantonsspital, St. Gallen

\section{Taxane-containing induction chemotherapy followed by definitive chemoradiotherapy}

\section{Outcome in patients with locally advanced head and neck cancer}

Radiotherapy (RT) and concomitant chemotherapy is currently regarded as the standard of care for unresectable locally advanced squamous cell carcinoma of the head and neck (HNSCC) with an absolute improvement of $8 \%$ in 5 -year survival due to concomitant chemotherapy [1]. In order to increase the outcome of patients with HNSCC, other attempts such as altered fractionated RT $[2,3]$ or induction chemotherapy have been explored. The non-inferiority of induction chemotherapy followed by RT vs. surgery and postoperative RT has been demonstrated for hypopharyngeal cancer [4]. Recently, the addition of taxanes to induction chemotherapy was investigated by the trials TAX 324 (induction chemotherapy followed by chemoradiotherapy) and EORTC 24971/ TAX 323 (induction chemotherapy followed by RT), which both showed a survival benefit of docetaxel, cisplatin, and fluorouracil (5-FU; TPF) vs. cisplatin and 5-FU (PF) induction $[5,6]$. Acute RT-related toxicity was deemed equal between the two respective treatment arms in both studies. Results from a phase II trial in Italy testing TPF induction chemotherapy followed by chemoradiotherapy vs. di- rect chemoradiotherapy are available suggesting a possible overall survival (OS) benefit for induction chemotherapy with similar acute RT-related toxicity rates [7]. Results from recently published phase III trials comparing induction chemotherapy with direct chemoradiation or surgery plus adjuvant chemoradiation, however, failed to demonstrate a survival benefit in favor of induction chemotherapy $[8,9,10]$.

In our clinic, patients were referred for induction chemotherapy in case of bulky and/or rapidly progressive primary tumors or lymph nodes where resection was not feasible. The intention was to treat rapidly local tumor growth and ameliorate symptoms like pain and nutritional status. The standard regimen was two to three cycles of induction chemotherapy. To achieve a maximal tumor control, concomitant cisplatin was designated as systemic agent. We report on the toxicity and oncological outcome after induction chemotherapy with TPF and chemoradiotherapy using cisplatin as concomitant agent in conjunction with state-of-the-art IMRT in patients with bulky tumors.

\section{Patients and methods}

\section{Patients and treatment}

The data of 40 patients who underwent at least one cycle of induction chemotherapy and were scheduled for definitive chemoradiotherapy between July 2004 and November 2010 were retrospectively analyzed. The study was approved by the local Ethics Committee. Clinical staging was based on radiologic findings as well as clinical examination. The case of each patient was discussed in an interdisciplinary tumor board. Most patients had bulky unresectable disease. In 3 patients with smaller but rapidly progressive tumors, one cycle of induction chemotherapy was given to prevent tumor growth during RT planning. Induction chemotherapy consisted of docetaxel at a dose of $75 \mathrm{mg} / \mathrm{m}^{2}$ followed by cisplatin $75 \mathrm{mg} / \mathrm{m}^{2}$ and fluorouracil $1,000 \mathrm{mg} / \mathrm{m}^{2}$ as continuous infusion for 4 days.

For treatment planning, a dedicated computed tomography (CT) scan with intravenous contrast material was used. Patients were immobilized in supine position using a thermoplastic mask covering 


\section{Tab. 1 Patient characteristics $(n=40)$}

$\mathrm{n}(\%)$

\begin{tabular}{ll}
\hline Age (years) & \\
\hline- Median (range) & $58(39-73)$ \\
\hline ECOG performance status & \\
\hline-0 or 1 & $32(80)$ \\
\hline-2 & $8(20)$ \\
\hline Gender & \\
\hline- Female & 9 \\
\hline- Male & 31 \\
\hline
\end{tabular}

Site

\begin{tabular}{ll}
\hline -Oral cavity & $3(7.5)$ \\
\hline - Oropharynx & $20(50)$ \\
\hline - Hypopharynx & $5(12.5)$
\end{tabular}

- Larynx $7(17.5)$

- Other $5(12.5)$

T classification $^{\text {a }}$

\begin{tabular}{ll}
\hline$-\mathrm{T} 0$ (CUP) & $2(5)$ \\
\hline$-\mathrm{T} 1$ & $0(0)$ \\
\hline$-\mathrm{T} 2$ & $2(5)$ \\
\hline$-\mathrm{T} 3$ & $11(27.5)$ \\
\hline$-\mathrm{T} 4$ & $25(62.5)$ \\
\hline
\end{tabular}

$\mathrm{N}$ classification $^{\mathrm{a}}$

\begin{tabular}{ll}
$-\mathrm{N} 0$ & $3(7.5)$ \\
\hline$-\mathrm{N} 1$ & $7(17.5)$ \\
\hline$-\mathrm{N} 2 \mathrm{a}$ & $0(0)$ \\
\hline$-\mathrm{N} 2 \mathrm{~b}$ & $15(37.5)$ \\
\hline$-\mathrm{N} 2 \mathrm{c}$ & $10(25)$ \\
\hline$-\mathrm{N} 3$ & $5(12.5)$ \\
\hline
\end{tabular}

Tumor stage ${ }^{\mathrm{a}}$

\begin{tabular}{ll}
\hline- III & $3(7.5)$ \\
\hline- IVa & $29(72.5)$ \\
\hline- IVb & $7(17.5)$ \\
\hline- Recurrence $^{b}$ & $1(2.5)$ \\
\hline Neck dissection $^{\text {N }}$ & $4(10)$
\end{tabular}

Tumor volume $(\mathrm{ml})$

-Median (range) 65 (2-392)

$\begin{array}{ll}\text { Induction chemotherapy } \\ \text {-TPF } & 27(67.5)\end{array}$

\begin{tabular}{ll}
\hline - Median cycles (range) & $3(1-5)$ \\
\hline $\begin{array}{l}\text {-TP/other Taxol-containing } \\
\text { regimen }\end{array}$ & $13(32.5)$
\end{tabular}
regimen

\begin{tabular}{lc}
\hline - Median cycles (range) & $2(1-4)$ \\
\hline Concomitant chemotherapy $(\mathrm{n}=34)$ \\
\hline-3 cycles cisplatin & $13(38)$ \\
\hline-2 cycles cisplatin & $11(32)$ \\
\hline-1 cycle cisplatin & $3(9)$ \\
\hline - Carboplatin & $3(9)$ \\
\hline - Cetuximab & $3(9)$ \\
\hline - None & $1(3)$ \\
\hline
\end{tabular}

TPF docetaxel, cisplatin, 5-FU, TP docetaxel, cisplatin, CUP cancer of unknown primary according to the 2002 AJCC classification bParapharyngeal nodal recurrence after resection of tongue primary and neck dissection and RT

Tab. 2 Acute RT-related toxicity $(n=33)$

\begin{tabular}{|llllll}
\hline & $\begin{array}{l}\text { Pre-RT dys- } \\
\text { phagia }\end{array}$ & Dysphagia & Mucositis & Dermatitis & $\begin{array}{l}\text { Maximum } \\
\text { toxicity by } \\
\text { patient }\end{array}$ \\
\hline Grade 0 & $24(73 \%)$ & $2(6 \%)$ & $4(12 \%)$ & $1(3 \%)$ & 0 \\
\hline Grade 1 & $3(9 \%)$ & 0 & $7(21 \%)$ & $7(21 \%)$ & $1(3 \%)$ \\
\hline Grade 2 & $2(6 \%)$ & $9(27 \%)$ & $14(43 \%)$ & $20(61 \%)$ & $7(21 \%)$ \\
\hline Grade 3 & $4(12 \%)$ & $22(67 \%)$ & $7(21 \%)$ & $5(15 \%)$ & $24(73 \%)$ \\
\hline Grade 4 & 0 & 0 & $1(3 \%)$ & 0 & $1(3 \%)$ \\
\hline
\end{tabular}

Tab. 3 Late RT-related toxicity $(\mathrm{n}=27)$

\begin{tabular}{|llllll}
\hline & Xerostomia & Dermatitis & Dysphagia & $\begin{array}{l}\text { Bone/carti- } \\
\text { lage necrosis }\end{array}$ & $\begin{array}{l}\text { Maximum } \\
\text { toxicity by } \\
\text { patient }\end{array}$ \\
\hline Grade 0 & $9(33 \%)$ & $10(37 \%)$ & $12(44 \%)$ & $23(85 \%)$ & $3(11 \%)$ \\
\hline Grade 1 & $6(22 \%)$ & $12(44 \%)$ & $8(30 \%)$ & 0 & $3(11 \%)$ \\
\hline Grade 2 & $8(30 \%)$ & $4(15 \%)$ & $6(22 \%)$ & 0 & $12(44 \%)$ \\
\hline Grade 3 & $4(15 \%)$ & $1(4 \%)$ & $1(4 \%)$ & 0 & $5(19 \%)$ \\
\hline Grade 4 & 0 & 0 & 0 & $4(15 \%)$ & $4(15 \%)$ \\
\hline
\end{tabular}

the head and shoulders. Target delineation was based on the pre-induction size and location of the tumor. We defined two different risk levels of clinical target volume (CTV): CTV72 comprised all gross tumor with an isotropic margin of $10-12 \mathrm{~mm}$ and was treated to $72 \mathrm{~Gy}$; CTV54 included elective areas and was treated to $54 \mathrm{~Gy}$. The resulting CTVs were expanded to planning target volumes (PTVs) by adding a symmetric 3-mm margin. The definition of elective nodal target volumes followed the recommendations proposed by Eisbruch et al. [11]. The PTVs were treated sequentially with a fractionation of 5 times 2 Gy per week. Preferably, two to three cycles of cisplatin $100 \mathrm{mg} / \mathrm{m}^{2}$ triweekly was applied as concurrent agent. Cetuximab or carboplatin was used alternatively. The prophylactic placement of a percutaneous endoscopic gastrostomy before chemoradiotherapy was recommended to every patient.

\section{Assessments and evaluations}

Remission after induction chemotherapy was assessed according to WHO criteria by a dedicated head and neck radiologist. Follow-up visits were arranged every 3-6 months for the first 2 years and biyearly thereafter. Toxicity during induction chemotherapy was graded according to the National Cancer Institute Common Terminology Criteria for Adverse Events (CTCAE) version 4.0. Only grade 3 or higher toxicity was taken into account. Acute and late RT-related toxicity was graded using the Radiation Therapy Oncology Group (RTOG) Radiation Morbidity Scoring Criteria. Additionally, treatment interruptions during chemoradiation and the time of feeding tube in situ were calculated.

\section{Statistical considerations}

The primary objective of the study was to assess acute and late RT-related toxicity including treatment gaps during chemoradiotherapy; secondary objectives were response to induction chemotherapy, locoregional recurrence-free survival (LRRFS), overall survival (OS), and relevant influencing factors for LRRFS and OS. Descriptive statistics included absolute and relative frequencies for categorical variables, and the median and range for quantitative variables. All time-to-event end points were calculated from the start of induction chemotherapy. Survival rates were calculated using the Kaplan-Meier product limit methodology. The influence of good response to induction chemotherapy [complete remission (cR) and partial remission ( $\mathrm{pR}$ )] vs. no response (no change) on LRRFS and OS was compared using a two-sided log-rank test. Univariate Cox regression analysis was used to study the influence of risk factors on LRRFS and OS. A p value of $<0.05$ was considered statistically significant. Statistical 
Strahlenther Onkol 2013 · 189:618-624 DOI 10.1007/s00066-013-0397-z

(c) Springer-Verlag Berlin Heidelberg 2013

\section{J.O. Brömme · M. Schmücking · A. Arnold · R. Giger · D. Rauch · D. Leiser · L. Plasswilm · A. Geretschläger $\cdot$ P. Ghadjar $\cdot$ D.M. Aebersold Taxane-containing induction chemotherapy followed by definitive chemoradiotherapy. Outcome in patients with locally advanced head and neck cancer}

\section{Abstract}

Background. Induction chemotherapy followed by definitive chemoradiotherapy is an intensified treatment approach for locally advanced squamous cell carcinoma of the head and neck (HNSCC) that might be associated with high rates of toxicity.

Materials and methods. The data of 40 consecutive patients who underwent induction chemotherapy with docetaxel-containing regimens followed by intensity-modulated radiotherapy (IMRT) and concomitant systemic therapy for unresectable locally advanced HNSCC were retrospectively analyzed. Primary objectives were RT-related acute and late toxicity. Secondary objectives were response to induction chemotherapy, locore- gional recurrence-free survival (LRRFS), overall survival (OS), and influencing factors for LRRFS and OS.

Results. The median follow-up for surviving patients was 21 months (range, 2-53 months). Patients received a median of three cycles of induction chemotherapy followed by IMRT to $72 \mathrm{~Gy}$. Three patients died during induction chemotherapy and one during chemoradiotherapy. Acute RT-related toxicity was of grade 3 and 4 in 72 and $3 \%$ of patients, respectively, mainly dysphagia and dermatitis. Late RT-related toxicity was mainly xerostomia and bone/cartilage necrosis and was of grade 3 and 4 in 15\% of patients.
One- and 2-year LRRFS and OS were 72 and $49 \%$ and 77 and $71 \%$, respectively. Conclusion. Induction chemotherapy followed by chemoradiotherapy using IMRT was associated with a high rate of severe acute and late RT-related toxicities in this selected patient cohort. Four patients were lost because of fatal complications. Induction chemotherapy did not compromise the delivery of full-dose RT; however, the use of three cycles of concomitant cisplatin was impaired.

Keywords Chemoradiotherapy $\cdot$ Induction chemotherapy · Radiotherapy · Head and neck cancer $\cdot$ Toxicity

\section{Taxanhaltige Induktionschemotherapie gefolgt von definitiver Radiochemotherapie. Resultate von Patienten mit lokal fortgeschrittenen Kopf-Hals-Tumoren}

\section{Zusammenfassung}

Hintergrund. Induktionschemotherapie gefolgt von definitiver kombinierter Radiochemotherapie ist eine intensivierte Behandlungsstrategie bei Patienten mit lokal fortgeschrittenen Plattenepithelkarzinomen der Kopf-Hals-Region, die mit hohen Toxizitätsraten verbunden sein könnte.

Material und Methoden. Wir haben eine retrospektive Analyse von 40 aufeinanderfolgenden Patienten mit nichtoperablen, lokal fortgeschrittenen Kopf-Hals-Tumoren durchgeführt, die eine docetaxelhaltige Induktionschemotherapie gefolgt von einer intensitätsmodulierten RT (IMRT) kombiniert mit einer systemischen Therapie erhielten. Das primäre Interesse galt den strahlentherapieassoziierten Toxizitäten. Weitere Ziele stellten das Ansprechen auf Induktionschemotherapie, lokoregionäre Rezidivfreiheit (LRRFS) und Gesamtüberleben (OS) sowie darauf bezogene Einflussfaktoren dar. Ergebnisse. Der Median der Nachkontrollzeit betrug 21 Monate (2-53 Monate). Die Patienten erhielten median 3 Zyklen Induktionschemotherapie gefolgt von IMRT bis 72 Gy. Während der Induktionschemotherapie verstarben 3 Patienten, während der Radiochemotherapie 1 Patient. Akute RT-assoziierte Toxizitäten vom Grad 3 und 4 traten bei 72 bzw. 3\% der Patienten auf, vor allem Dysphagie und Dermatitis. Späte RT-assoziierte Toxizitäten, bei denen es sich bei jeweils 15\% der Patienten um Grad 3 und 4 handelte, betrafen Xerostomie und Knorpel-/Knochen- nekrosen. Das LRRFS nach 1 bzw. 2 Jahren betrug 72 bzw $49 \%$, das OS 77 bzw. $71 \%$. Schlussfolgerungen. Indiktionschemotherapie gefolgt von Radiochemotherapie mit IMRT war in dieser definierten Patientenkohorte mit einem hohen Anteil schwerer Toxizitäten verbunden. Während der Behandlung verstarben 4 Patienten. Die Induktionschemotherapie schränkte die Durchführung der Radiotherapie nicht ein, die konkomitante Gabe von 3 Zyklen Cisplatin war jedoch eingeschränkt.

\section{Schlüsselwörter}

Radiochemotherapie .

Induktionschemotherapie - Strahlentherapie . Kopf-Hals-Tumoren · Toxizität analysis was performed using SPSS version 17.0 (SPSS Inc., Chicago, IL, USA).

\section{Results}

\section{Patient characteristics}

Patient characteristics are summarized in - Tab. 1. Initial staging consisted of magnetic resonance imaging (MRI) or CT; 21 patients additionally underwent positron emission tomography (PET)/CT. Three patients underwent neck dissec- tion after induction chemotherapy, one patient before. The median follow-up for surviving patients was 21 months (range, 2-53.0 months). The median tumor volume was $65 \mathrm{ml}$, with $75 \%$ of patients presenting tumors larger than $30 \mathrm{ml}$.

\section{Induction chemotherapy, toxicity, and response}

During induction chemotherapy, 8 patients (20\%) developed grade 3-4 toxicity, mainly neutropenia. One patient died be- cause of a septic complication, 2 patients died of unknown reasons after two cycles of induction chemotherapy. Two patients showed a deterioration in general condition and were referred to palliative treatment; 1 patient declined RT. Thus, 6 patients did not undergo definitive chemoradiotherapy (15\%). Complete remission after induction chemotherapy was observed in 4 out of 40 patients (10\%), partial remission in 27 patients $(68 \%)$, no change in 8 patients $(20 \%)$, and 1 patient was not assessable. Patients receiv- 


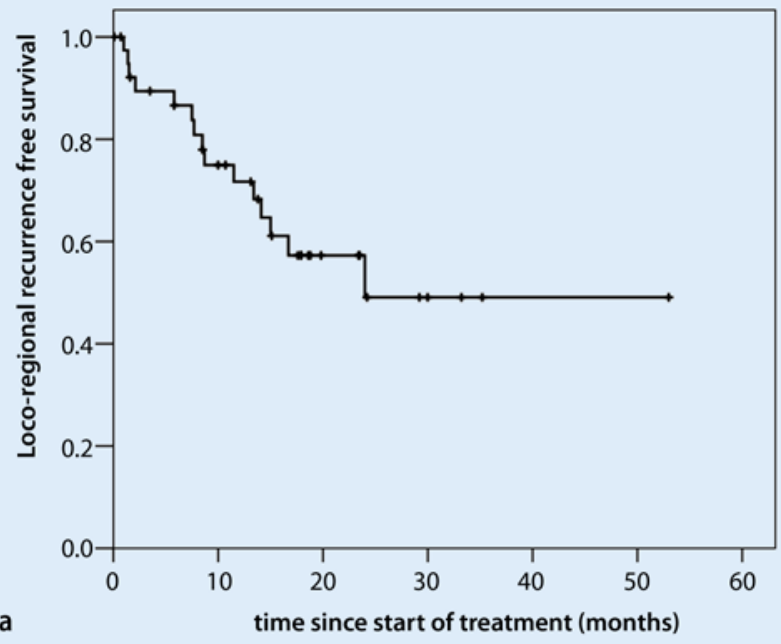

a
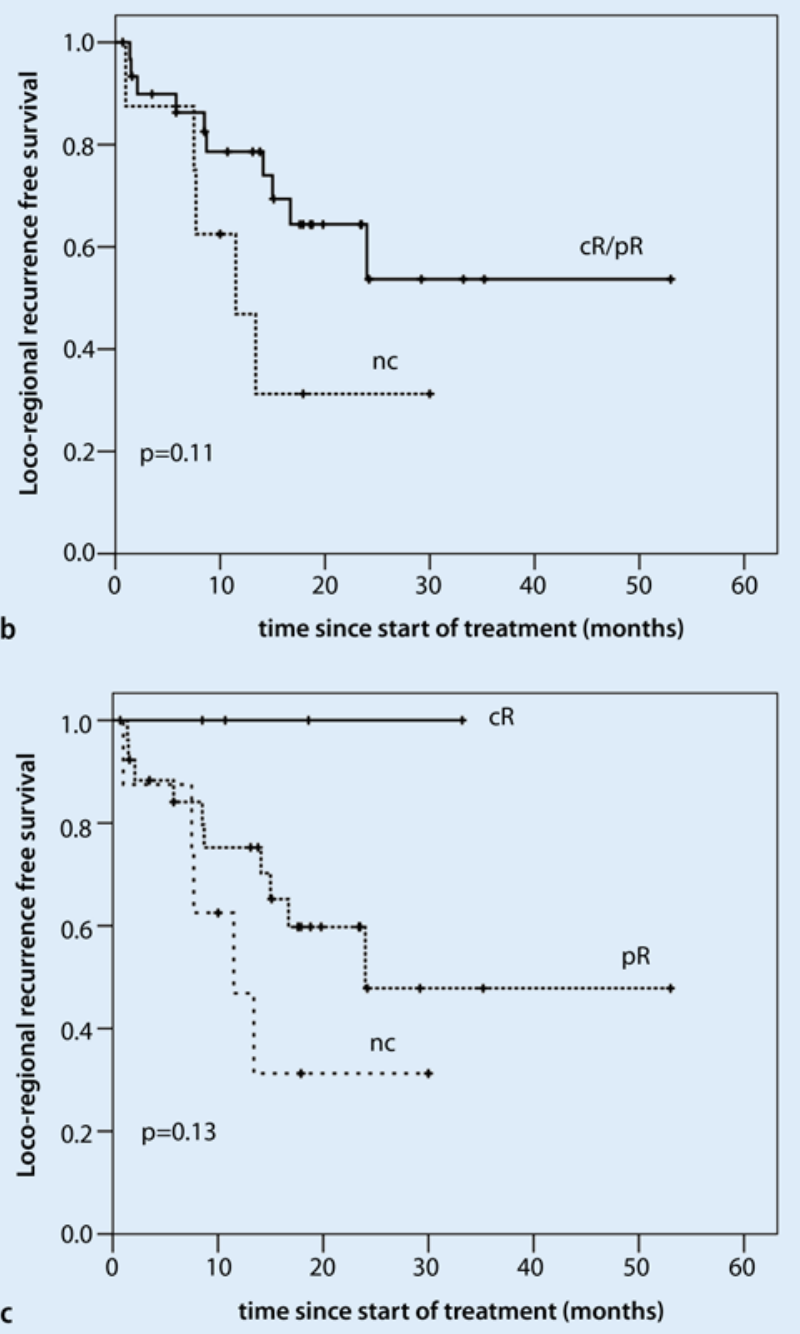

tient first refused RT and then started 7 months after induction chemotherapy. Four patients had interruptions of RT related to acute toxicity of 5 days. One patient died during chemoradiotherapy because of a feeding tube-related infection after the first cycle of cisplatin.

Data for acute and late RT-related toxicity were available for 33 and 27 patients, respectively. The results are summarized in Tab. 2 and $\bullet$ Tab. 3. Eight patients (23\%) received gastrostomy prior to RT because of swallowing deficits, 12 patients (35\%) had prophylactic feeding tube placement at the beginning of RT. The median time of feeding tube in situ was 12 months (range, 2-38 months).

Five patients experienced local recurrence; 1 a local tumor persistence, 2 merely regional recurrence, and 4 patients had both local and regional recurrence. The 3 patients not undergoing chemoradiotherapy were taken into account as tumor persistence. At 1 and 2 years, LRRFS was 72 , and $49 \%$, respectively. The influence of risk factors on LRRFS is shown in $\bullet$ Fig. 1 and $\bullet$ Tab. 4.

Four patients developed distant metastasis 6, 7, 14, and 20 months after treatment, respectively. All but one of these patients had an earlier locoregional recurrence.

A total of 13 deaths were noted. Besides 3 patients who died before undergoing chemoradiotherapy, 2 patients with deterioration of general condition under induction chemotherapy and 1 patient refusing RT subsequently underwent palliative therapy and eventually died of tumor progression. One patient died during chemoradiotherapy of a feeding tube complication and 6 patients died during follow-up, 5 because of tumor progression, 1 of pulmonary disease.

Fig. $1<$ Locoregional recurrence-free survival of all patients (a) and stratified according to tumor response after induction chemotherapy $(\mathbf{b}, \mathbf{c})$ ing three to five cycles of induction chemotherapy had a significantly higher rate of $\mathrm{cR} / \mathrm{pR}$ compared to patients with one to two cycles (Fisher's exact test, $\mathrm{p}=0.03$ ).

\section{Chemoradiotherapy, RT-related toxicity, and outcome}

The median time from the last cycle of induction chemotherapy to the start of RT was 45 days (range, $0-203$ days). One pa-
One- and 2-year OS was 77 and $71 \%$, respectively, with a median OS of 34 months. The analysis of risk factors on OS is shown in $\bullet$ Fig. 2 and $\bullet$ Tab. 5.

\section{Discussion}

We identified considerable rates of RT-related acute and late toxicities after induction chemotherapy followed by chemoradiotherapy in our selected patient cohort with unresectable locally advanced $\mathrm{HN}$ - 

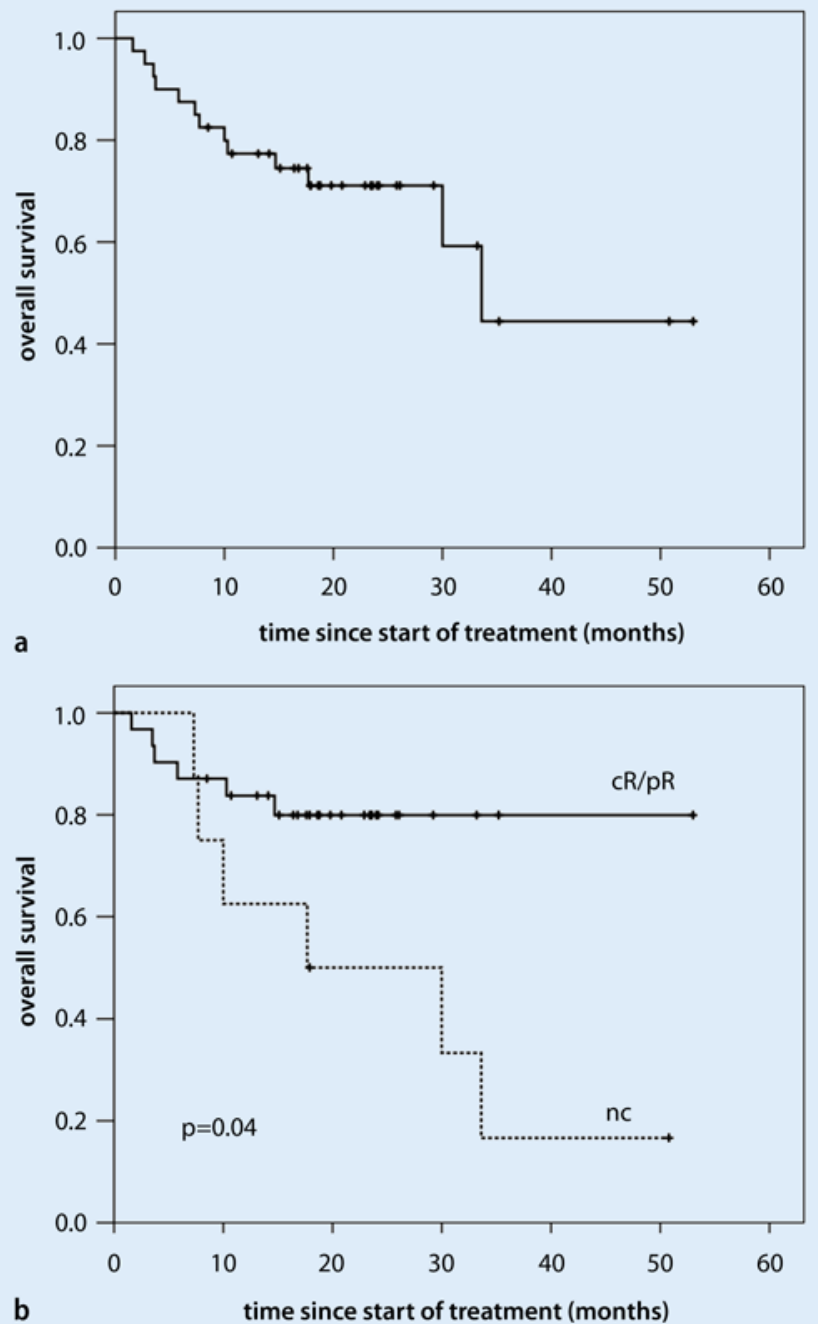

b

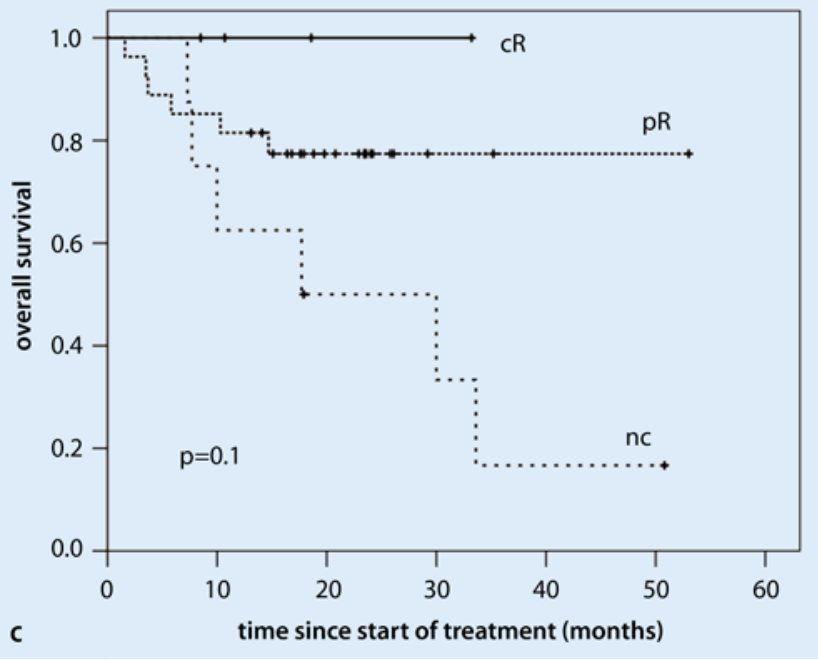

retrospective trial showed that both techniques yielded the same locoregional control and overall survival but with significantly less toxicity when using IMRT [14]. In a direct comparison of TPF induction followed by chemoradiotherapy vs. direct chemoradiotherapy, equal rates of grade $3 / 4$ dysphagia in $21 \%$ vs. $20 \%$ and mucositis in $28 \%$ vs. $37 \%$ of patients were found [7], which are considerably lower than in our study. However, the RT technique was not stated and an uncommon score was used impairing direct comparison. In our study, all patients but one undergoing chemoradiotherapy completed RT as prescribed. This compares favorably to TAX 324 , where $21 \%$ of patients in the TPF arm did not receive full RT [5].

To avoid toxicity-related treatment breaks, use of gastrostomy feeding tubes during irradiation of advanced HNSSC is standard in our institution, even though this procedure has been discussed controversially [15]. Patients received pain medication and dedicated skin care. When necessary, patients were hospitalized to administer i.v. fluids. In our cohort, only 4 patients (12\%) had toxicity-related treatment interruptions of 5 days, known to be associated with decreased survival [16]. This is within the range of $10 \%$ found in conventional chemoradiotherapy [17]. During chemoradiotherapy, 38\% of the patients received three cycles of cisplatin, $32 \%$ received two cycles. A retrospective analysis of patients treated by the same regimen found results of $5 \%$ receiving three cycles, $61 \%$ receiving two cycles, and $29 \%$ receiving one cycle of concurrent cisplatin [12]. These rates are considerably lower than reported in the standard RTOG 91-11 study [18]. Induction chemotherapy thus seems to impair concomitant chemotherapy with cisplatin, but not the delivery of RT once started.

Data on late toxicity after induction chemotherapy followed by chemoradiotherapy for HNSCC are sparse. Our rates of late RT-related toxicity of $44 \%$ grade 2 , $19 \%$ grade 3 , and $15 \%$ grade 4 are comparable with the data in other publications. Van Gestel et al. [19] described late toxicity of any grade in 16 of 18 patients treated with induction chemotherapy followed by chemoradiotherapy, mainly xerostomia. In a long-term analysis of the TAX 324 tri-
SCC. Acute grade 3 dysphagia was present in $67 \%$ of patients and grade 3 mucositis in $21 \%$. Very high rates of acute toxicity have been reported in an analysis of patients undergoing TPF induction chemotherapy followed by $3 \mathrm{D}$ conformal chemoradiotherapy with grade 3 skin toxicity in $73 \%$ and grade 3 mucosal toxicity in $85 \%$ of patients [12]. The development of IMRT significantly reduced xerostomia when compared to 3D-CRT in a randomized controlled trial [13]. Recently, a large
Fig. $2<$ Overall surand stratified accordfter induction chemotherapy $(\mathbf{b}, \mathbf{c})$ 
Tab. 4 Univariate Cox regression analysis for risk factors influencing locoregional recurrence-free survival $(n=40)$

\begin{tabular}{llll}
\hline Risk factor & HR & Cl & p value \\
\hline Age $\geq 58$ years & 0.2 & $0.04-0.8$ & 0.02 \\
\hline Gender male & 1.5 & $0.4-5.3$ & 0.53 \\
\hline ECOG 2 & 8.2 & $2.2-30$ & 0.01 \\
\hline T classification T4 & 1.9 & $0.6-5.5$ & 0.27 \\
\hline Subsite hypopharynx & 1.8 & $0.5-6.4$ & 0.39 \\
\hline N classification N2c-N3 & 1.1 & $0.4-3.1$ & 0.83 \\
\hline Tumor volume $>65 \mathrm{ml}$ & 4.5 & $1.2-17.8$ & 0.03 \\
\hline $\begin{array}{l}\text { Induction chemo- } \\
\text { therapy 3-5 cycles }\end{array}$ & 1.0 & $0.3-3.1$ & 1.0 \\
\hline $\begin{array}{l}\text { Response to induction } \\
\text { chemotherapy no } \\
\text { change }\end{array}$ & 2.4 & $0.8-7.0$ & 0.12 \\
\hline $\begin{array}{l}\text { Concomitant chemo- } \\
\text { therapy other regimen }\end{array}$ & 0.7 & $0.2-3.2$ & 0.7 \\
\hline $\begin{array}{l}\text { Total treatment time } \\
>\text { 20 weeks }\end{array}$ & 0.5 & $0.2-1.7$ & 0.29 \\
\hline HR hazard ratio, Cl 95\% confidence interval aFor 33 patients completing therapy & \\
\hline
\end{tabular}

Tab. 5 Univariate Cox regression analysis for risk factors influencing overall survival $(n=40)$

\begin{tabular}{llll}
\hline Risk factor & HR & Cl & p value \\
\hline Age $\geq 58$ years & 0.75 & $0.23-2.5$ & 0.63 \\
\hline Gender male & 1.6 & $0.4-7.2$ & 0.55 \\
\hline ECOG 2 & 4.3 & $1.4-13.2$ & 0.01 \\
\hline T classification T4 & 3.5 & $0.77-16.3$ & 0.11 \\
\hline Subsite hypopharynx & 2.0 & $0.6-6.6$ & 0.3 \\
\hline N classification N2c-N3 & 1.3 & $0.43-3.9$ & 0.65 \\
\hline Tumor volume $>65 \mathrm{ml}$ & 6.5 & $0.77-55.3$ & 0.08 \\
\hline $\begin{array}{l}\text { Induction chemo- } \\
\text { therapy 3-5 cycles }\end{array}$ & 0.5 & $0.2-1.6$ & 0.24 \\
\hline $\begin{array}{l}\text { Response to induction } \\
\text { chemotherapy no } \\
\text { change }\end{array}$ & 3.2 & $1.0-10.1$ & 0.05 \\
\hline $\begin{array}{l}\text { Concomitant chemo- } \\
\text { therapy other regimen }\end{array}$ & 1.2 & $0.2-6.1$ & 0.8 \\
\hline $\begin{array}{l}\text { Total treatment time } \\
>20 \text { weeks }\end{array}$ & 1.0 & $0.2-4.5$ & 0.98 \\
\hline$H R$ hazard ratio, Cl95\% confidence interval aFor 33 patients completing therapy & \\
\hline
\end{tabular}

al, only half of the surviving patients could be assessed for the surrogate parameter of presence of tracheotomy (7\%) and feeding tube dependency (3\%) [20]. A recent long-term analysis after concurrent hyperfractionated RT vs. hyperfractionated RT alone found grade 3 dysphagia in $24 \%$ and grade 4 in $3 \%$ of patients in the combined treatment arm [21]. In our patient cohort, osteoradionecrosis of the mandible and necrosis of laryngeal cartilage presented the most severe late toxicity. Surgical interventions like debridement or even resection and tracheotomy might become necessary, but were not observed in our patient cohort.

In our series after induction chemotherapy, we observed a $\mathrm{CR}$ in $10 \%$ of patients, $\mathrm{pR}$ in $68 \%$ of patients, and no change in $20 \%$ of patients. The TAX 324 group reported a slightly higher overall response rate after induction chemotherapy of $72 \%$ in the TPF group. The percentage of patients with a complete response was $17 \%$ in the TPF group [5].

We found an LRRFS at 1 and 2 years of 72 and $49 \%$, respectively. The OS rate was $77 \%$ at 1 year and $71 \%$ at 2 years, with median OS being 34 months. The TAX
324 study group [5] found a median OS of 59 months and a 3 year-OS of $62 \%$ for stage 4 patients treated with TPF induction. PFS was $49 \%$ at 3 years. The phase II study of Paccagnella comparing induction chemotherapy vs. direct chemoradiotherapy [7] suggested a prolonged OS of $61 \%$ vs. $57 \%$ and PFS of $56 \%$ vs. $45 \%$ at 2 years in favor of TPF induction. However, in the recently published abstracts of the DeCIDE and PARADIGM phase III trials comparing induction chemotherapy with direct chemoradiotherapy, no benefit in OS (75\% vs. $73 \%$ at 24 months and $73 \%$ vs. $78 \%$ at 36 months) or PFS ( $67 \%$ vs. $73 \%$ at 36 months) was found $[8,9]$. The same applies for induction chemotherapy followed by surgery and adjuvant chemoradiotherapy [10]. The issue of tumor load as an independent risk factor for outcome in HNSCC has been shown in the literature [22] and was confirmed in our study (- Tab.4). The relevance of induction chemotherapy with respect to gross tumor volume remains unclear. Older phase III trials investigating the role of induction chemotherapy found no benefit for local control and OS, but a significant decrease in distant failure [23]. Distant metastasis occurred in our collective mainly after locoregional recurrence in $10 \%$ of patients; one solely distant failure was seen (2.5\%). The DeCIDE trial found a lower cumulative incidence of distant failure in the induction chemotherapy arm, but this did not translate into OS benefit. Patients treated with standard chemoradiotherapy showed a rate of distant failure between $7 \%$ at 20 months [23] and $25.3 \%$ at 3 years [17]. These data need careful interpretation, as patients with an uncontrollable locoregional recurrence are usually not screened for distant metastases.

In the current study, we found an OS benefit for patients with good response to induction chemotherapy $(\mathrm{p}=0.04)$, with a trend regarding locoregional control. Kaplan-Meier plots demonstrate a clear separation of the survival curves according to response on induction therapy. The better OS in spite of nonsignificant differences in LRRFS for good response might be related to the fact that patients with good remission had longer survival with palliative chemotherapy (4 patients) and RT (2 patients) The most important influence on 
outcome was seen for performance score, stressing the importance of clinical patient evaluation. This aspect is well known from direct chemoradiation [24].

Remarkably, 3 patients (7\%) died in the interval between induction chemotherapy and the start of RT with one death directly attributable to sepsis in neutropenia; 1 patient died during RT. Fewer fatal complications were reported in prospective trials $[5,7]$, which may be related to the stricter inclusion criteria concerning performance score and comorbidity. However, the DeCIDE trial showed three deaths (3.5\%) during induction and nine (10\%) during subsequent chemoradiation as opposed to four deaths in direct chemoradiation [8].

Owing to the relatively short follow-up and the retrospective nature of this study, our results should be considered as the hypothetic base for further studies with longer follow-up.

\section{Conclusion}

TPF induction chemotherapy followed by chemoradiotherapy outside a study protocol is associated with a high rate of acute and late RT-related toxicities. In our study 4 patients were lost because of fatal complications, at least 1 of them with a direct link to chemotherapy-induced neutropenia. Induction chemotherapy did not compromise the delivery of fulldose RT; however, the use of three cycles of concomitant cisplatin was impaired.

\section{Corresponding address}

Prof. Dr. D.M. Aebersold, M.D.

Department of Radiation Oncology, Inselspital, Bern University Hospital and University of Bern Freiburgstrasse, 3010 Bern

Switzerland

daniel.aebersold@insel.ch

Conflict of interest. On behalf of all authors, the corresponding author states that there are no conflicts of interest.

\section{References}

1. Pignon JP, Maitre A le, Maillard E et al (2009) Metaanalysis of chemotherapy in head and neck cancer (MACH-NC): an update on 93 randomised trials and 17,346 patients. Radiother Oncol 92:4-14
2. Bourhis J, Overgaard J, Audry H et al (2006) Hyperfractionated or accelerated radiotherapy in head and neck cancer: a meta-analysis. Lancet 368:843854

3. Kubes J, Cvek J, Vondracek V et al (2011) Accelerated radiotherapy with concomitant boost technique ( $69.5 \mathrm{~Gy} / 5$ weeks): an alternative in the treatment of locally advanced head and neck cancer. Strahlenther Onkol 187:651-655

4. Lefebvre JL, Chevalier D, Luboinski B et al (1996) Larynx preservation in pyriform sinus cancer: preliminary results of a European Organization for Research and Treatment of Cancer phase III trial. EORTC Head and Neck Cancer Cooperative Group. J Natl Cancer Inst 88:890-899

5. Posner MR, Hershock DM, Blajman CR et al (2007) Cisplatin and fluorouracil alone or with docetaxel in head and neck cancer. N Engl J Med 357:17051715

6. Vermorken JB, Remenar E, Herpen C van et al (2007) Cisplatin, fluorouracil, and docetaxel in unresectable head and neck cancer. N Engl J Med 357:1695-1704

7. Paccagnella A, Ghi MG, Loreggian L et al (2010) Concomitant chemoradiotherapy versus induction docetaxel, cisplatin and 5 fluorouracil (TPF) followed by concomitant chemoradiotherapy in locally advanced head and neck cancer: a phase II randomized study. Ann Oncol 21:1515-1522

8. Cohen EEW KT, Kocherginsky M, Huang CH et al (2012) DeCIDE: a phase III randomized trial of docetaxel (D), cisplatin (P), 5-fluorouracil (F) (TPF) induction chemotherapy (IC) in patients with N2/ N3 locally advanced squamous cell carcinoma of the head and neck (SCCHN). J Clin Oncol 30 (suppl., abstr. 5500)

9. Haddad RI RG, Tishler RB, Adkins D et al (2012) The PARADIGM trial: a phase III study comparing sequential therapy (ST) to concurrent chemoradiotherapy (CRT) in locally advanced head and neck cancer(LANHC). J Clin Oncol 30 (suppl., abstr. 5501)

10. Zhong LP, Zhang CP, Ren GX et al (2013) Randomized phase III trial of induction chemotherapy with docetaxel, cisplatin, and fluorouracil followed by surgery versus up-front surgery in locally advanced resectable oral squamous cell carcinoma. J Clin Oncol 31:744-751

11. Eisbruch A, Foote RL, O'Sullivan B et al (2002) Intensity-modulated radiation therapy for head and neck cancer: emphasis on the selection and delineation of the targets. Semin Radiat Oncol 12:238249

12. Prestwich RJ, Oksuz DC, Dyker K et al (2011) Feasibility and efficacy of induction docetaxel, cisplatin and 5-fluorouracil chemotherapy combined with cisplatin concurrent chemoradiotherapy for nonmetastatic Stage IV head-and-neck squamous cell carcinomas. Int J Radiat Oncol Biol Phys 81:e237e243

13. Nutting CM, Morden JP, Harrington KJ et al (2011) Parotid-sparing intensity modulated versus conventional radiotherapy in head and neck cancer (PARSPORT): a phase 3 multicentre randomised controlled trial. Lancet Oncol 12:127-136

14. Lambrecht $M$, Nevens D, Nuyts $S$ (2013) Intensity-modulated radiotherapy vs. parotid-sparing 3D conformal radiotherapy: effect on outcome and toxicity in locally advanced head and neck cancer. Strahlenther Onkol

15. Paleri V Patterson J (2010) Use of gastrostomy in head and neck cancer: a systematic review to identify areas for future research. Clin Otolaryngol 35:177-189
16. Fesinmeyer MD, Mehta V, Blough D et al (2010) Effect of radiotherapy interruptions on survival in medicare enrollees with local and regional head-and-neck cancer. Int J Radiat Oncol Biol Phys 78:675-681

17. Bourhis J, Sire C, Graff P et al (2012) Concomitant chemoradiotherapy versus acceleration of radiotherapy with or without concomitant chemotherapy in locally advanced head and neck carcinoma (GORTEC 99-02): an open-label phase 3 randomised trial. Lancet Oncol 13:145-153

18. Forastiere AA, Goepfert $H$, Maor M et al (2003) Concurrent chemotherapy and radiotherapy for organ preservation in advanced laryngeal cancer. N Engl J Med 349:2091-2098

19. Van Gestel D, Van Den Weyngaert D, Schrijvers D et al (2011) Intensity-modulated radiotherapy in patients with head and neck cancer: a European single-centre experience. Br J Radiol 84:367-374

20. Lorch JH, Goloubeva O, Haddad RI et al (2011) Induction chemotherapy with cisplatin and fluorouracil alone or in combination with docetaxel in locally advanced squamous-cell cancer of the head and neck: long-term results of the TAX 324 randomised phase 3 trial. Lancet Oncol 12:153-159

21. Ghadjar P, Simcock M, Studer G et al (2012) Concomitant cisplatin and hyperfractionated radiotherapy in locally advanced head and neck cancer: 10-year follow-up of a randomized phase III trial (SAKK 10/94). Int J Radiat Oncol Biol Phys 82:524531

22. Studer G, Lutolf UM, El-Bassiouni M et al (2007) Volumetric staging (VS) is superior to TNM and AJCC staging in predicting outcome of head and neck cancer treated with IMRT. Acta Oncol 46:386394

23. Studer G, Seifert B Glanzmann C (2008) Prediction of distant metastasis in head neck cancer patients: implications for induction chemotherapy and pretreatment staging? Strahlenther Onkol 184:580585

24. Sadat F, Wienke A, Dunst J et al (2012) Survival of patients with head and neck cancer. Impact of physical status and comorbidities. Strahlenther Onkol188:62-70 